\title{
Bovine neuronal vesicular glutamate transporter activity is inhibited by ergovaline and other ergopeptines ${ }^{1}$
}

\author{
Y. Xue, ${ }^{\star}$ S. F. Liao, ${ }^{*}$ J. R. Strickland,† J. A. Boling, ${ }^{\star}$ and J. C. Matthews ${ }^{\star 2}$ \\ *Department of Animal and Food Sciences, University of Kentucky, Lexington 40546 \\ †USDA-ARS, Forage-Animal Production Research Unit, Lexington, KY 40546
}

\begin{abstract}
L-Glutamate $(\mathrm{Glu})$ is a major excitatory neurotransmitter responsible for neurotransmission in the vertebrate central nervous system. Vesicular Glu transporters VGLUT1 and VGLUT2 concentrate $(50 \mathrm{mM})$ Glu [Michaelis constant (measuring affinity), or $K_{\mathrm{m}},=1$ to $4 \mathrm{mM}$ ] into synaptic vesicles (SV) for subsequent release into the synaptic cleft of glutamatergic neurons. Vesicular Glu transporter activity is dependent on vacuolar $\mathrm{H}^{+}$-ATPase function. Previous research has shown that ergopeptines contained in endophyteinfected tall fescue interact with dopaminergic and serotoninergic receptors, thereby affecting physiology regulated by these neuron types. To test the hypothesis that ergopeptine alkaloids inhibit VGLUT activity of bovine cerebral SV, SV were isolated from cerebral tissue of Angus-cross steers that were naive to ergot alkaloids. Immunoblot analysis validated the enrichment of VGLUT1, VGLUT2, synaptophysin 1, and vacuolar $\mathrm{H}^{+}$-ATPase in purified SV. Glutamate uptake assays demonstrated the dependence of SV VGLUTlike activity on the presence of ATP, $\mathrm{H}^{+}$-gradients, and $\mathrm{H}^{+}$-ATPase function. The effect of ergopeptines on VGLUT activity was evaluated by ANOVA. Inhibitory competition $\left(\mathrm{IC}_{50}\right)$ experiments revealed that VGLUT-mediated Glu uptake $(\mathrm{n}=9)$ was inhibited by ergopeptine alkaloids: bromocriptine $(2.83 \pm 0.59 \mu M)$ $<$ ergotamine $(20.5 \pm 2.77 \mu M)<$ ergocornine $(114 \pm$ $23.1 \mu M)<$ ergovaline $(137 \pm 6.55 \mu M)$. Subsequent ergovaline kinetic inhibition analysis $(\mathrm{n}=9$; Glu $=$ $0.05,0.10,0.50,1,2,4,5 \mathrm{mM}$ ) demonstrated no change in apparent $K_{\mathrm{m}}$. However, the maximum reaction rate $\left(V_{\max }\right)$ of Glu uptake was decreased when evaluated in the presence of 50,100, and $200 \mu M$ ergovaline, suggesting that ergovaline inhibited SV VGLUT activity

\footnotetext{
Received July 9, 2010.

Accepted March 12, 2011.

${ }^{1}$ Supported by a USDA-ARS Special Cooperative Agreement, the

${ }^{2}$ Corresponding author: jmatthew@uky.edu
} University of Kentucky, and the Kentucky Agricultural Experiment Station (Publ. No. 10-07-122).
\end{abstract}

through a noncompetitive mechanism. The findings of this study suggest cattle with fescue toxicosis may have a decreased glutamatergic neurotransmission capacity due to consumption of ergopeptine alkaloids.

Key words: ergot alkaloid, fescue toxicosis, glutamatergic neurotransmission, SLC17

\section{INTRODUCTION}

It is generally accepted that L-glutamate $(\mathbf{G l u})$ is the major excitatory neurotransmitter responsible for neurotransmission in the vertebrate central nervous system (Moriyama and Yamamoto, 2004; Krnjević, 2010). In the presynaptic region of glutamatergic neurons, cytosolic Glu primarily is generated by phosphate-dependent glutaminase, concentrated into synaptic vesicles (SV) by low-affinity (Michaelis constant, or $\boldsymbol{K}_{\mathrm{m}},=1$ to $4 \mathrm{mM}$ ) vesicular Glu transporters (VGLUT; Fremeau et al., 2001; 2004), and then released from SV into the synaptic clefts (Shigeri et al., 2004). Three known mammalian proteins are capable of VGLUTlike activity (VGLUT 1-3). Vesicular Glu transporter 1 (SLC17A7) and VGLUT3 (SLC17A8) are expressed primarily in brain tissue (Shigeri et al., 2004), whereas VGLUT 2 (SLC17A6) is expressed in brain and many peripheral tissues, including anterior pituitary LH gonadotrophs (Hrabovszky et al., 2006), small intestinal epithelial L-cells, and pancreatic $\alpha$-cells (Moriyama and Yamamoto, 2004; Moriyama and Omote, 2008). Critical to glutamatergic neurotransmission is the tremendous capacity of VGLUT to concentrate Glu (up to $50 \mathrm{mM}$ ) into SV. The driving force for VGLUT function is a high inside-to-outside vesicle $\mathrm{H}^{+}$gradient produced by vacuolar $\mathrm{H}^{+}$-ATPase (Ozkan and Ueda, 1998; Ikemoto et al., 2003). The 2 types of vacuolar $\mathrm{H}^{+}$-ATPase also display differential patterns of expression. Vacuolar $\mathrm{H}^{+}$ATPase 1 is expressed exclusively in the brain, whereas vacuolar $\mathrm{H}^{+}$-ATPase 2 is expressed in nonneuronal tissue (Peng et al., 1999).

Tall fescue (Lolium arundinaceum) is a grass commonly used in grazing systems in the United States. Neotyphodium coenophialum is an endophytic fungus that infects most tall fescue pastures. However, the 
Table 1. Composition (\% of DM) of diet fed to finishing steers

\begin{tabular}{lc}
\hline Ingredient & $\begin{array}{c}\text { Composition } \\
(\%)\end{array}$ \\
\hline Ground corn & 61.6 \\
Soybean meal & 11.4 \\
Urea & 10 \\
Limestone & 10 \\
Trace mineral mix $^{1}$ & 5.5 \\
Fat & 1.1 \\
Vitamin premix & \\
Rumensin $80^{3}$ & 0.2 \\
Tylan $40^{3}$ & 0.16 \\
\hline
\end{tabular}

${ }^{1}$ The trace mineralized salt $(0.06 \% \mathrm{Ca}, 1.2 \% \mathrm{~S}, 92.9 \% \mathrm{NaCl})$ contained $(\mathrm{mg} / \mathrm{kg}) \mathrm{Fe}(9,290), \mathrm{Zn}(5,520), \mathrm{Mn}(4,792), \mathrm{Cu}(1,838)$, I $(120)$, Co (69), and Se (19).

${ }^{2}$ The vitamin premix $(\mathrm{IU} / \mathrm{kg})$ consisted of vitamin A $(1,818,812)$, vitamin D (363,000), and vitamin E (227).

${ }^{3}$ Elanco, Indianapolis, IN.

ergot alkaloids produced by Neotyphodium coenophialum can cause an assortment of health and production problems (collectively referred to as fescue toxicosis) in cattle consuming endophyte-infected tall fescue forage or seed. Animal production symptoms of fescue toxicosis include decreased feed intake (Jackson et al., 1984), weight gain (Mizinga et al., 1992; Brown et al., 2009), reproductive efficiency (Monroe et al., 1988), milk production (Stuedemann and Hoveland, 1988), or combinations of these symptoms. Physiologic symptoms of fescue toxicosis typically include decreased plasma LH and prolactin concentrations (Browning, Jr. et al., 1997b, 1998), elevated constriction of reproductive (Dyer, 1993) and systemic (Aiken et al., 2007, 2009) vasculature, and hyperthermia associated with heat stress (Hemken et al., 1981). In SV isolated from rat brain, kinetic analyses has shown that VGLUT-like activity is inhibited by synthetic (bromocriptine) and natural (ergotamine, $\alpha$-ergocriptine) ergopeptides, with that by bromocriptine being by competitive interactions (Carlson et al., 1989).

The goal of the present study was to validate a bovine SV experimental model and then to use this model to test the hypothesis that bovine SV VGLUT activity is inhibited by ergopeptines, including ergovaline, a suspected agent of many fescue toxicosis symptoms.

\section{MATERIALS AND METHODS}

\section{Materials}

L- $\left[2,3-{ }^{3} \mathrm{H}\right]$ glutamate $\left({ }^{3}[\mathrm{H}]\right.$ glutamate; $1,147,000 \mathrm{MBq} /$ mmol) was purchased from GE Healthcare (Buckinghamshire, UK). Synthetic ergovaline tartrate (ergovaline, $93 \%$ purity) was synthesized by and purchased from Forrest T. Smith (Auburn University, AL). All other reagents were purchased from Sigma (St. Louis,
MO), unless noted otherwise. All chemicals used were of the highest purity available.

\section{Preparation of Bovine Cerebral SV}

All experimental procedures were approved by the University of Kentucky Institutional Animal Care and Use Committee. The whole brain was collected from 8 different Angus-cross steers that had been fed a diet consisting of $75 \%$ corn, $15 \%$ corn silage, and $10 \%$ protein/mineral supplement (Table 1) for 120 to $140 \mathrm{~d}$ and had ad libitum access to fresh water. Steers were raised at the University of Kentucky Animal Research Center and had never been exposed to ergot alkaloids. Steers were serially slaughtered ( 1 steer per day, BW $=646.03$ $\pm 80.29 \mathrm{~kg}$ ) at the University of Kentucky Meats Laboratory such that carcasses could be recovered (Brown et al., 2009).

Bovine SV were prepared as described by Kish and Ueda (1989) with minor modifications. During the SV isolation procedure, brain tissue fractions $(\mathrm{F})$ were collected to determine the degree of enrichment produced by the SV isolation procedure by immunoblot analysis. The prepared SV and brain tissue fractions were stored in liquid nitrogen and at $-80^{\circ} \mathrm{C}$, respectively. The protein concentration of brain tissue fractions and the final SV fraction were quantified using a modified Lowry assay, using BSA as a standard (Kilberg, 1989). The amount of SV collected ranged from 0.9 to $2.9 \mathrm{mg}$ from 128 to $150 \mathrm{~g}$ of isolated cerebral cortex.

\section{Immunoblot Analysis Validation of SV Preparation}

The relative content of VGLUT1, VGLUT2, vacuolar $\mathrm{H}^{+}$-ATPase, synaptophysin1, and EAAC1 proteins in brain tissue and SV fractions was determined by immunoblot analyses to ascertain the protein profile of SV, thus serving as a validation of the SV-enrichment procedure (see Figure 1). The general immunoblot analysis regimen used was as described previously (Howell et al., 2001; Brown et al., 2009) except that proteins in the various isolation fractions $(10 \mu \mathrm{g} /$ lane $)$ were separated by $12 \%$ SDS-PAGE (Laemmli, 1970). Briefly, all primary antibodies were hybridized in $\mathrm{pH} 7.5$ blocking solution $[1 \% \mathrm{wt} / \mathrm{vol}$ nonfat dry milk (Carnation, Nestle, Solon, OH), $30 \mathrm{~m} M$ Tris, $200 \mathrm{~m} M \mathrm{NaCl}, 0.1 \%$ Tween 20 ( vol/vol)] for $1.5 \mathrm{~h}$ at room temperature with agitation. Antibodies were used as followed: rabbit anti-rat VGLUT1 $(0.1 \mu \mathrm{g} / \mathrm{mL}$; affinity-purified polyclonal antibody; Synaptic Systems, Göttingen, Germany), rabbit anti-rat VGLTU2 $(0.1 \mu \mathrm{g} / \mathrm{mL}$; polyclonal antibody; Synaptic Systems), rabbit anti-rat vacuolar $\mathrm{H}^{+}$-ATPase (0.5 $\mathrm{\mu g} / \mathrm{mL}$; polyclonal antiserum; Synaptic Systems), rabbit anti-rat synaptophysin $1(0.1 \mu \mathrm{g} / \mathrm{mL}$; polyclonal 
antiserum; Synaptic Systems), and rabbit anti-human EAAC1 $(1 \mu \mathrm{g} / \mathrm{mL}$ of polyclonal antibody; Santa Cruz Biotechnology, Inc., Santa Cruz, CA; Brown et al., 2009). After washing, membranes were incubated with horseradish peroxidase-conjugated goat anti-rabbit IgG- (1:10,000; Jackson Immunochemistry Laboratories, West Grove, PA) or horseradish peroxidase-conjugated donkey anti-rabbit IgG-horse radish peroxidase (1:2,000; Amersham, Arlington Heights, IL) for $1 \mathrm{~h}$ at room temperature to detect VGLUT1, VGLUT2, vacuolar $\mathrm{H}^{+}$-ATPase, and synaptophysin 1, or EAAC1, respectively. Immunoreactive products were visualized using a chemiluminescence kit (Pierce Biotechnology, Inc., Rockford, IL). After exposure to autoradiographic film (Research Products International Corp., Mt. Prospect, IL), digital images of immunoreactive species were recorded and quantified using the VersaDoc imaging system and Quality One Program (version 4.2.3; Bio-Rad Laboratories, Hercules, CA), as described by Brown et al. (2009). Apparent migration weights $\left(M_{r}\right)$ were determined against the $\mathrm{M}_{\mathrm{r}}$ of a 25 to $250-\mathrm{kDa}$ protein standard (Bio-Rad Laboratories).

The use of primary non-bovine primary antibodies was validated by pre-adsorption of primary antibodies with their respective antigen polypeptides before use in the immunoblot procedure. The commonly used secondary antibody described above was found to be specific for the presence of each primary antibody (data not shown). Immunoreaction products for synaptophysin 1, VGLUT1, VGLUT2, and vacuolar $\mathrm{H}^{+}$ATPase in cerebral tissue homogenates $(10 \mu \mathrm{g})$ were all abolished if pre-adsorbed ( $\mu \mathrm{g}: \mu \mathrm{g})$ with increasing amounts of their antigens, thus validating their use against bovine orthologs (data not shown). The abolishing antibody:antigen ratios were 1:4, 1:1, 1:0.04, and 1:0.04 for synaptophysin 1, VGLUT1, VGLUT2, and vacuolar $\mathrm{H}^{+}$-ATPase, respectively. Attempts to validate the use of an anti-rat VGLUT3 antibody in bovine cerebral tissue failed (data not shown).

\section{SV Glu Uptake Assays}

Standard Glu Uptake Conditions. Vesicular glutamate uptake was assayed as described previously (Carlson et al., 1989; Kish and Ueda, 1989) with minor modifications. The standard Glu uptake reaction (100 $\mu \mathrm{L}$ ) was conducted in 5-mL polypropylene tubes and the standard uptake solution consisted of $10 \mu \mathrm{g}$ of SV,

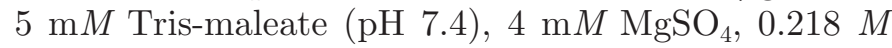
sucrose, $0.02 \mathrm{~m} M$ potassium L-aspartate, $2 \mathrm{~m} M$ ATP neutralized with Tris-base, $4 \mathrm{mM} \mathrm{KCl}$, and $50 \mu M$ potassium Glu, 0.74 MBq/mL (0.65 $\mu M\left[{ }^{3} \mathrm{H}\right]$ glutamate). $\mathrm{L}$-Aspartate was included in the standard incubation mixture to block any residual system $\mathrm{X}_{\mathrm{AG}}{ }^{-}$-mediated
Glu uptake activity. The standard uptake solution was prepared, and the uptake reaction initiated, by combining $80 \mu \mathrm{L}$ of SV solution $[6.25 \mathrm{~m} M$ Tris-maleate $(\mathrm{pH}$ 7.4), $5 \mathrm{mM} \mathrm{MgSO}_{4}, 0.273 M$ sucrose, and $0.025 \mathrm{mM}$ potassium L -aspartate] that contained $10 \mu \mathrm{g}$ SV and that had been pre-incubated at $30^{\circ} \mathrm{C}$ for 5 min with $20 \mu \mathrm{L}$ of Glu solution [10 mM ATP neutralized with Tris-base, $20 \mathrm{mM} \mathrm{KCl}$, and $0.25 \mathrm{~m} M$ potassium L -Glu, and $3.25 \mu M(3.7 \mathrm{MBq} / \mathrm{mL})$ of $\left[{ }^{3} \mathrm{H}\right]$ glutamate]. After an appropriate incubation period at $30^{\circ} \mathrm{C}$, depending on the experiment, Glu uptake was terminated by the addition of $2.0 \mathrm{~mL}$ of stop solution (ice-cold $0.15 \mathrm{M} \mathrm{KCl}$ ), followed by immediate filtration of the standard uptake solution through Millipore HAWP filters $(25 \mathrm{~mm}$, $0.45 \mu \mathrm{m}$ ), using a 1225 sampling manifold (Millipore Corp., Bedford, MA) connected to a vacuum source. The incubation tubes were rinsed 3 times with $2 \mathrm{~mL}$ of stop solution, adding the stop solution to the filter after each rinse. The filters then were washed 6 more times with $2 \mathrm{~mL}$ of stop solution. Each filter was dissolved in $7 \mathrm{~mL}$ of liquid scintillation cocktail (SX 25; Fisher Scientific, Fair Lawn, NJ) and the radioactivity of the filter measured by using a liquid scintillation spectrophotometer (Beckman LS 900; Beckman Coulter, Inc., Brea, CA). Recorded counts per minute were converted to disintegrations per min using a standard quench curve. Glutamate uptake values were determined as the product of 0 -s Glu uptake-corrected disintegrations per minute $(\mathrm{dpm})$ and the specific activity of the buffer. For each experiment the 0 -s Glu uptake value was determined by adding the $20-\mu \mathrm{L}$ Glu/ATP mixture to the $80-\mu \mathrm{L}$ SV solution, mixing the resulting standard uptake solution by vortexing, and then stopping the Glu uptake reaction as just described. The 0-s Glu uptake value was subtracted from all Glu uptake reactions and the observed Glu uptake activities of SV represent pmol of Glu uptake $10 \mu \mathrm{g}$ of SV protein ${ }^{-1} \cdot 1.5 \mathrm{~min}^{-1}$.

Optimization of VGLUT-Mediated Glu Uptake Conditions for $\boldsymbol{S} \boldsymbol{V}$. The level of $50 \mu M$ Glu was used to optimize VGLUT-mediated uptake conditions because preliminary work with SV found that this level was in the linear range of uptake from 0.5 to 4 min (data not shown), consistent with that reported by others (Carlson et al., 1989; Kish and Ueda, 1989) and in subsequent experimentation (see Figure 2). To determine the ATP dependency and the optimal (linear) duration for Glu uptake by SV, Glu uptake by SV was measured using standard Glu uptake reaction solutions that contained none or $2 \mathrm{mM}$ ATP at $0,0.75$, $1.5,3,6,12$, and $24 \mathrm{~min}$. The ATP-dependent uptake was taken as the numerical difference of Glu uptake in the presence and absence of ATP.

Assessment of VGLUT-Like Activity in SV. The effects of potential inhibitors on SV Glu uptake 
A

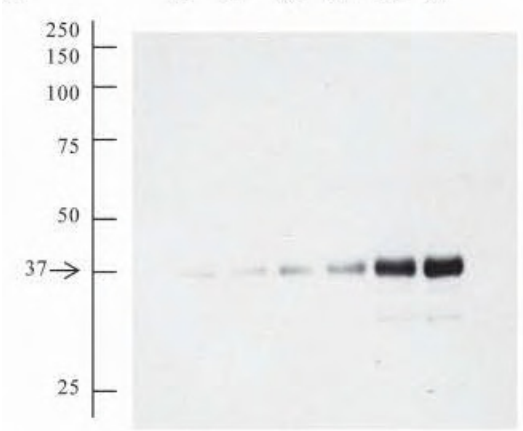

B

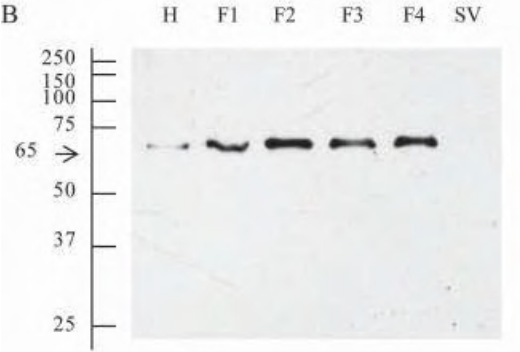

C

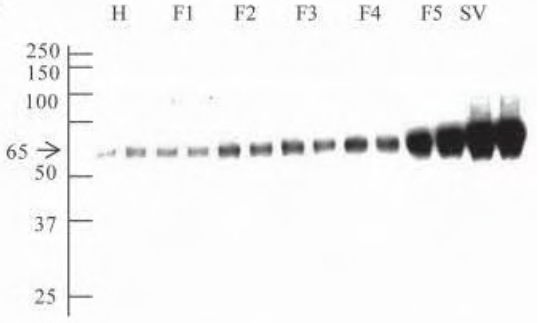

D

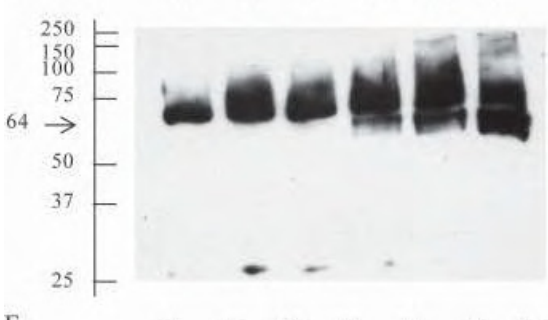

E

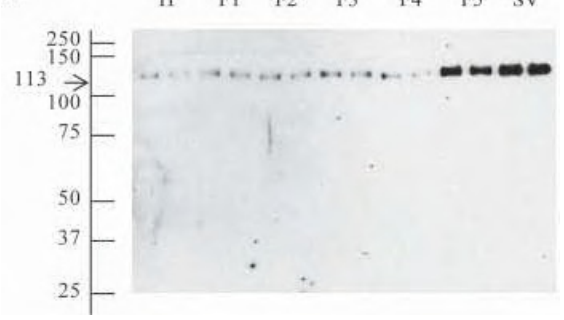

Figure 1. Immunoblot analysis of bovine cerebral synaptic vesicle (SV) enrichment. The presence of synaptophysin 1 (A), excitatory anionic transporter 1 (EAAC1; B), vesicular glutamate transporter 1 (VGLUT1; C) and 2 (VGLUT2; D), and vacuolar $\mathrm{H}^{+}$-ATPase (E) in serial fractions $(\mathrm{F})$ during purification of synaptic vessels $(\mathrm{SV})$ from bovine cerebral homogenate $(\mathrm{H})$ were determined by immunoblot analysis $(10 \mu \mathrm{g} /$ lane $)$. For synaptophysin 1 and EAAC1, immunoblots are representative of 2 separate animals. For VGLUT1, VGLUT2, and vacuolar $\mathrm{H}^{+}$-ATPase, duplicate tissue fractions from 2 animals are presented in parallel lanes for a given fraction. The apparent migration weight markers $(\mathrm{kDa})$ are indicated to the left of the immunoblots. activity, either to validate the presence of VGLUT and vacuolar $\mathrm{H}^{+}$-ATPase activity in SV or to test the effect of ergopeptines on VGLUT activity, were calculated as a percentage of the observed control SV uptake (pmol of Glu uptake $10 \mu \mathrm{g}$ of SV protein ${ }^{-1} \cdot 1.5 \mathrm{~min}^{-1}$ ). As appropriate, none (control), $1 \mu \mathrm{L}$ of $1 \mathrm{~m} M$ rose bengal (dissolved in water), $1 \mu \mathrm{L}$ of $0.1 \mu M$ bafilomycin (dissolved in $99.9 \%$ dimethyl sulfoxide; DMSO), $1 \mu \mathrm{L}$ of $10 \mathrm{~m} M$ bromocriptine (dissolved in DMSO), or $1 \mu \mathrm{L}$ of $1.25 \mathrm{~m} M$ carbonyl cyanide- $p$-trifluoromethoxyphenylhydrazone (FCCP) (dissolved in DMSO) was prepared and added to the SV solution. The effect of adding 1, 2 , and $3 \%$ DMSO to the SV solution was tested and found not to affect $(P=0.292) \mathrm{SV}$ Glu uptake (data not shown).

The potential effects of ergovaline, ergotamine, and ergocornine on Glu uptake by SV were assessed by adding $0,5,10,50,100,200,400$, and $600 \mu M$ of these compounds to the SV solution and determining their relative inhibitory competition $\left(\mathrm{IC}_{50}\right)$ values. $\mathrm{An} \mathrm{IC}_{50}$ value for bromocriptine was assessed using $0,5,10,50$, 100,200 , and $400 \mu M$ of bromocriptine. Bromocriptine, ergotamine, and ergocornine were dissolved in 1 or $2 \%$ DMSO as appropriate, whereas ergovaline was dissolved in 1 or $2 \%$ methanol. The effect of adding 1 , 2 , and $3 \%$ methanol to the SV solution was tested and found not to affect $(P=0.354) 50 \mu M$ Glu uptake by SV (data not shown).

Kinetic analysis of ergovaline inhibition of SV Glu uptake activity $\left[\mathrm{K}_{m}\right.$ and maximum reaction rate $\left.\left(\mathbf{V}_{\max }\right)\right]$ was performed by assessing the effects of adding 0,50 , 100 , and $200 \mu M$ ergovaline to the SV solution on 0.05 , $0.1,0.50,1,2,4$, and $5 \mathrm{~m} M$ Glu uptake by SV. Kinetic parameters $\left(\mathrm{IC}_{50}, K_{\mathrm{m}}\right.$, and $\left.V_{\max }\right)$ were calculated using GraphPad Prism 5 (GraphPad Software, Inc., La Jolla, $\mathrm{CA}$ ) software using the log (inhibitor) versus responsevariable slope equation and the Michaelis-Menten equation, respectively.

\section{Statistical Analyses}

For each uptake experiment, the experimental units were appropriate amounts of SV preparation (typically $10 \mu \mathrm{g})$. The effect of time, uptake solution treatment (L-aspartate, ATP, or ergopeptines), or kinetic values $\left(\mathrm{IC}_{50}, K_{\mathrm{m}}\right.$, and $\left.V_{\max }\right)$ on the ability of $\mathrm{SV}$ to absorb Glu was evaluated by ANOVA, using the general linear model of SAS (version 9.2; SAS Inst., Inc., Cary, NC). When appropriate, protected Fisher LSD procedures of SAS were used to separate means. To describe the shape of ATP-dependent Glu uptake curves, the first-, second-, and third-order variable of time was included in the model statement to determine linear, quadratic, and cubic effects. 


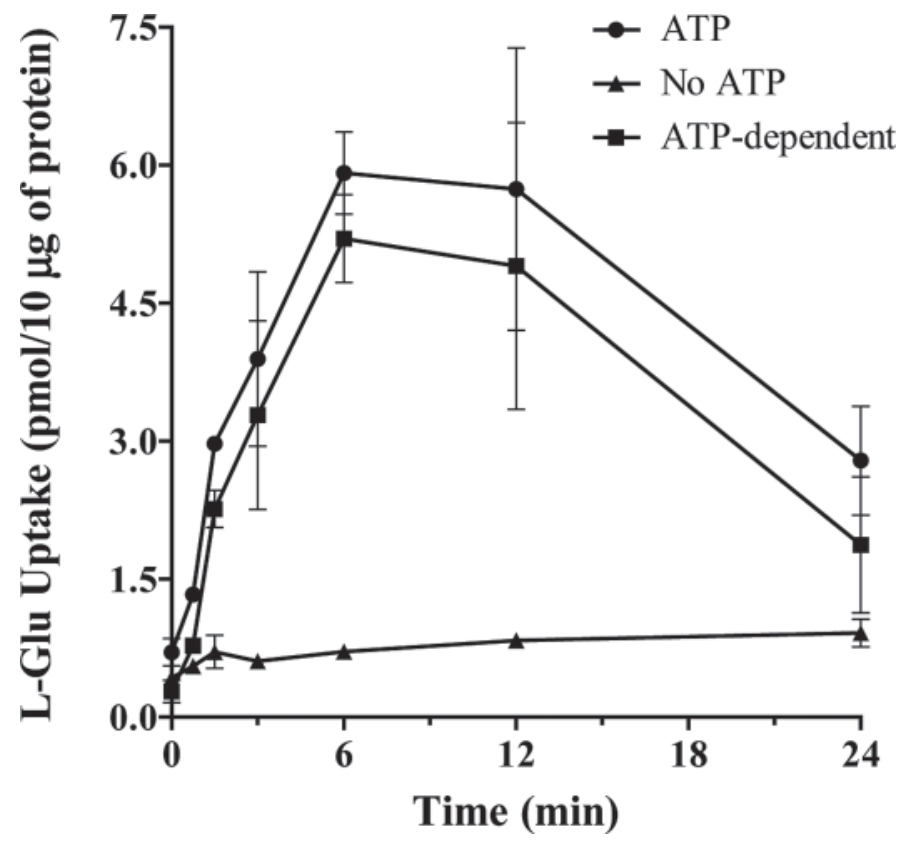

Figure 2. By-minute time-course of L-glutamate (Glu) uptake (pmol/10 $\mu \mathrm{g}$ of protein) by bovine cerebral synaptic vesicles (SV) in the absence or presence of ATP $(2 \mathrm{mM})$. Values are means \pm standard error $(\mathrm{n}=6)$ of $50 \mu M \mathrm{Glu}$ uptake assayed in 2 separate experiments after $0,0.75,1.5,3,6,12$, and $24 \mathrm{~min}$ of uptake. Time effect: $P<$ 0.001; ATP effect: $P<0.001$; time $\times$ ATP interaction effect: $P<$ 0.001. ATP-dependent uptake was taken as the numerical difference of Glu uptake in the presence and absence of ATP. Quadratic time effect on ATP-dependent Glu uptake: $P<0.001$; cubic time effect on ATPdependent Glu uptake: $P<0.001$.

\section{RESULTS}

\section{Enrichment of VGLUT Proteins in Bovine SV}

Having validated the use of anti-rat antibodies for detection of bovine SV proteins (Materials and Methods), the presence of known VGLUT activity-associated proteins isolated in SV was evaluated by immunoblot analysis. As noted above, synaptophysin 1 can be a marker for SV membrane enrichment, whereas EAAC1 is a marker for plasma membranes of neuronal cells (Shigeri et al., 2004). Consistent with the expected enrichment of cellular membranes, both synaptophysin 1 and EAAC1 were enriched from homogenate through the fraction 4 (synaptosomal proteins) step (Figure $1 \mathrm{~A}$ and 1B). Consistent with the enrichment of intact SV from synaptosomal proteins, synaptophysin 1 (37 $\mathrm{kDa}$ ) was further enriched in the final SV preparation, whereas EAAC1 was not detected in the SV preparation. Critically, as seen for the synaptic vesicle marker synaptophysin 1 , the relative abundances of VGLUT1 (65 kDa), VGLUT2 (64 kDa), and vacuolar $\mathrm{H}^{+}$-ATPase $(113 \mathrm{kDa})$ also were serially enriched during the preparation of SV from cerebral homogenates (Figure 1C,
$1 \mathrm{D}$, and $1 \mathrm{E})$. In summary of this immunoblot analysis, the SV preparation was greatly enriched for the SV marker protein (synaptophysin 1) and proteins responsible for SV VGLUT activity (VGLUT1, VGLUT2, and vacuolar $\mathrm{H}^{+}$-ATPase), and de-enriched for a plasma membrane marker (EAAC1).

\section{Development of a VGLUT Activity Regimen for SV}

To demonstrate that bovine SV uptake of Glu was ATP-dependent, and to determine the geometric relationship between accumulated Glu and time of SV uptake, Glu uptake by SV was measured in the presence and absence of ATP in the standard uptake solution over a 24 -min period (Figure 2$)$. Time $(P<0.001)$ and ATP $(P<0.001)$ effects, and a time $\times$ ATP interaction were observed. The interaction apparently reflects the 5-fold increase in total Glu uptake in the presence of ATP after 6 min, followed by stabilization of the rate of Glu uptake from 6 to $12 \mathrm{~min}$, and subsequent decrease from 12 to $24 \mathrm{~min}$. In contrast, the rate of total Glu uptake in the absence of ATP essentially had plateaued by 0.75 min. The ATP-dependent Glu uptake curve was cubic $(P<0.001)$ in shape, paralleling the total Glu uptake curve. That is, ATP-dependent Glu uptake by SV reached a half-maximal level in 3 min and a maximal level by 6 min. Decreases in ATPdependent Glu uptake at time longer than 12 min are likely due to diminished ATP concentration in the SV. Based on these results, all subsequent SV Glu uptake measurements were made in the presence of $0.02 \mathrm{mM}$ $\mathrm{L}$-aspartate and $2 \mathrm{mM}$ ATP for $1.5 \mathrm{~min}$, to optimize VGLUT-like activity.

\section{Glu Uptake by SV Is Inhibited by Compounds Known to Interact with Proteins Responsible for VGLUT Activity}

The effect of putative vacuolar $\mathrm{H}^{+}$-ATPase and VGLUT inhibitors on Glu uptake by SV was determined to further validate the presence of VGLUT-specific uptake activity in SV (Figure 3). Glutamate uptake was inhibited $84.53 \pm 21.45 \%$ by bafilomycin and $89.40 \pm$ $3.73 \%$ by FCCP, indicating that bovine SV Glu uptake was dependent on vacuolar $\mathrm{H}^{+}$-ATPase function and an inwardly-directed $\mathrm{H}^{+}$gradient. Glu uptake by SV also was inhibited $99.54 \pm 6.23 \%$ by rose bengal and 77.98 $\pm 6.69 \%$ by bromocriptine, indicating the necessity of VGLUT activity for SV uptake of Glu.

Subsequently, the SV prepared from 5 additional animals were found to possess FCCP and bromocriptine sensitivity, thus VGLUT activity. These SV preparations then were used in experiments to determine the effect of ergopeptines on VGLUT activity of bovine SV. 


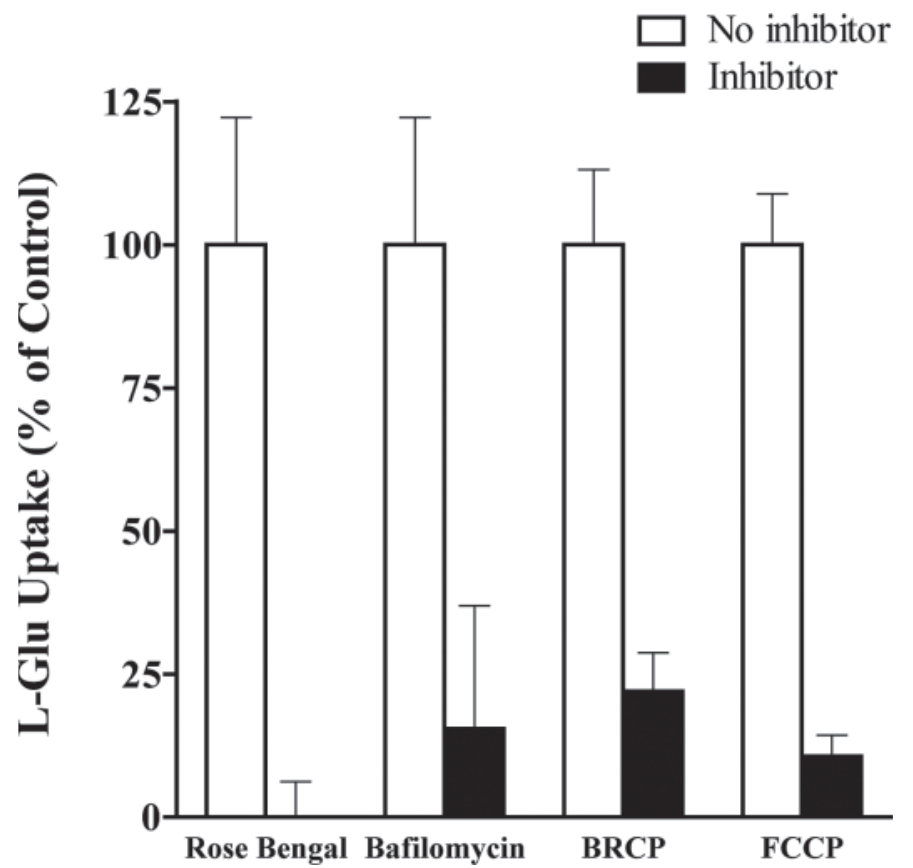

Figure 3. Characterization of VGLUT activity-mediated uptake of L-glutamate (Glu) uptake by bovine cerebral synaptic vesicles (SV). Values (\% of control uptake) are means \pm standard error of $50 \mu M$ Glu uptake (pmol.10 $\mu \mathrm{g}$ of SV protein ${ }^{-1} \cdot 1.5 \mathrm{~min}^{-1}$ ) by SV assayed in 2 separate experiments in the presence of no inhibitor (control; $\mathrm{n}=6)$ or $1 \mu M$ bafilomycin $(\mathrm{n}=6), 12.5 \mu M$ carbonyl cyanide- $p$ trifluoromethoxyphenylhydrazone (FCCP; $\mathrm{n}=9$ ), $10 \mu M$ rose bengal $(\mathrm{n}=6)$, or $100 \mu M$ bromocriptine (BRCP, $\mathrm{n}=6)$. Control uptake of Glu was $1.88 \pm 0.42,2.90 \pm 0.2,1.88 \pm 0.42,2.42 \pm 0.32$, respectively. Inhibitor effect: $P \leq 0.02$.

\section{Ergopeptines Differentially Inhibit SV VGLUT-Mediated Glu Uptake}

Ergopeptines contain a common ergoline ring and a peptide moiety but differ in the composition of their side groups. Inhibitory competition experiments were conducted to determine if these structurally-related compounds equally affect VGLUT activity (Figure 4). Synaptic vesicle VGLUT Glu uptake $(50 \mu M)$ was differentially inhibited $(P \leq 0.048)$ by each of the ergopeptines: bromocriptine $(2.83 \pm 0.59 \mu M)<$ ergotamine $(20.5 \pm 2.77 \mu M)<$ ergocornine $(114 \pm 23.1 \mu M)$ $<$ ergovaline $(137 \pm 6.55 \mu M)$.

\section{Ergovaline Inhibits VGLUT Activity in a Noncompetitive Manner}

To gain insight into the mechanism(s) by which ergovaline inhibited VGLUT activity, a kinetic analysis of the effect of ergovaline on Glu uptake by SV was performed (Figure 5). The apparent $K_{m}$ for Glu uptake in the absence of ergovaline was $1.53 \pm 0.18 \mathrm{mM}$, a value consistent with the reported $K_{m}(1$ to $4 \mathrm{mM})$ by rat SV in rodents (Carlson et al., 1989) and for cloned and overexpressed VGLUT (Bellocchio et al., 2000; Fremeau et al., 2001; Schäfer et al., 2002). The apparent $K_{\mathrm{m}}$ in the presence of $50 \mu M(0.77 \pm 0.14 \mathrm{mM})$, $100 \mu M(0.61 \pm 0.26 \mathrm{mM})$, and $200 \mu M(1.16 \pm 0.34$ $\mathrm{m} M)$ ergovaline did not change $(P=0.332)$ compared with the $K_{\mathrm{m}}$ in the absence of inhibitors $(1.53 \mathrm{mM})$. This finding indicates that ergovaline does not inhibit Glu uptake by SV through competition with Glu for binding.

In contrast, $V_{\max }$ values in the presence of $50 \mu \mathrm{M}$ $(39.9 \pm 14.5 \mathrm{pmol} / 1.5 \mathrm{~min}), 100 \mu M(38.8 \pm 2.28$ $\mathrm{pmol} / 1.5 \mathrm{~min})$, and $200 \mu M(30.4 \pm 4.40 \mathrm{pmol} / 1.5$ min) ergovaline were equally $(P \geq 0.765)$ decreased $(P$ $=0.016)$ compared with that in the absence of ergovaline ( $V_{\max }=148 \pm 55.1 \mathrm{pmol}$ of Glu uptake $10 \mu \mathrm{g}$ of SV protein ${ }^{-1} \cdot 1.5 \mathrm{~min}^{-1}$ ). Therefore, ergovaline appeared to inhibit VGLUT activity by a noncompetitive mechanism.

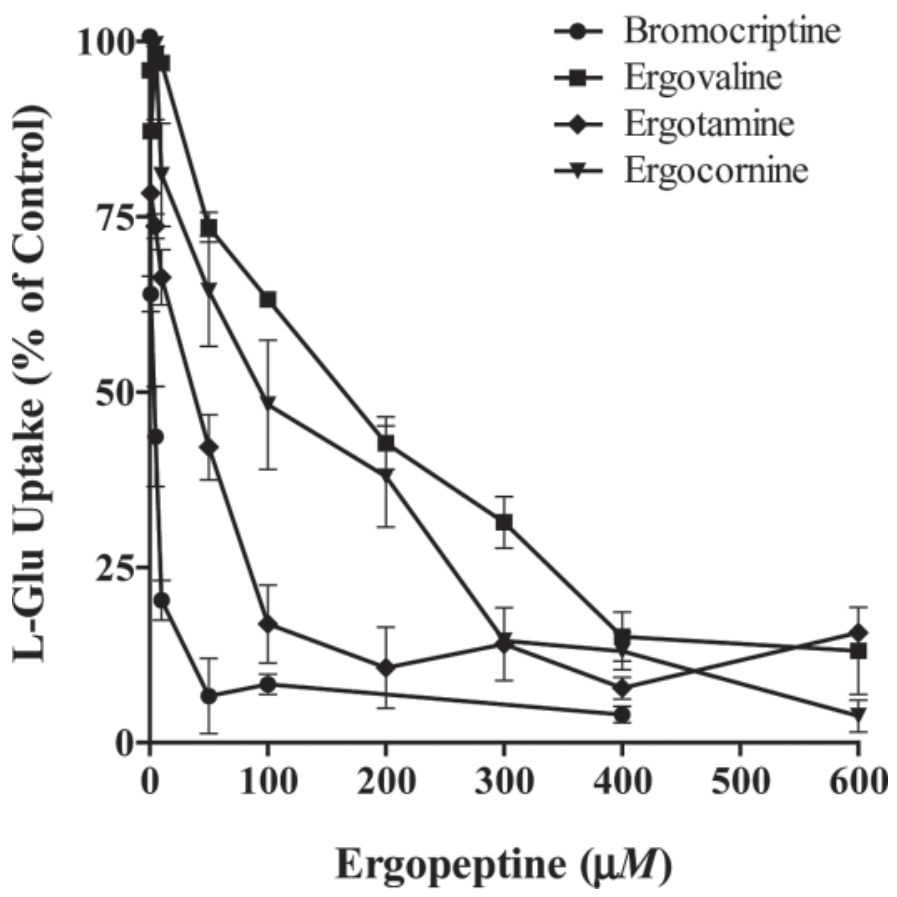

Figure 4. Ergopeptine inhibition [inhibitory competition $\left(\mathrm{IC}_{50}\right)$ determination] of L-glutamate (Glu) uptake by bovine cerebral synaptic vesicles (SV). Values (\% of control uptake) are means $(\mathrm{n}=9) \pm$ standard error of $50 \mu \mathrm{M}$ Glu uptake (pmol.10 $\mu \mathrm{g}$ of SV protein ${ }^{-1} \cdot 1.5$ $\mathrm{min}^{-1}$ ) by $\mathrm{SV}$ in the presence of 0 (control), and 5, 10, 50, 100, 200, 400 , and $600 \mu M$ of ergovaline, ergotamine, or ergocornine; and 5, 10, $50,100,200$, and $400 \mu M$ of bromocriptine, from 3 separate experiments. The mean control Glu uptake values for bromocriptine, ergotamine, ergocornine, and ergovaline were $2.62 \pm 0.62,3.12 \pm 0.93,3.32$ $\pm 0.69,2.73 \pm 0.42$, respectively. Differential ergopeptine effect: $P \leq$ $0.048 . \mathrm{IC}_{50}$ values were $2.83 \pm 0.59,20.5 \pm 2.77,114 \pm 23.1$, and 137 $\pm 6.55 \mu M$ for bromocriptine, ergotamine, ergocornine, and ergovaline, respectively. 


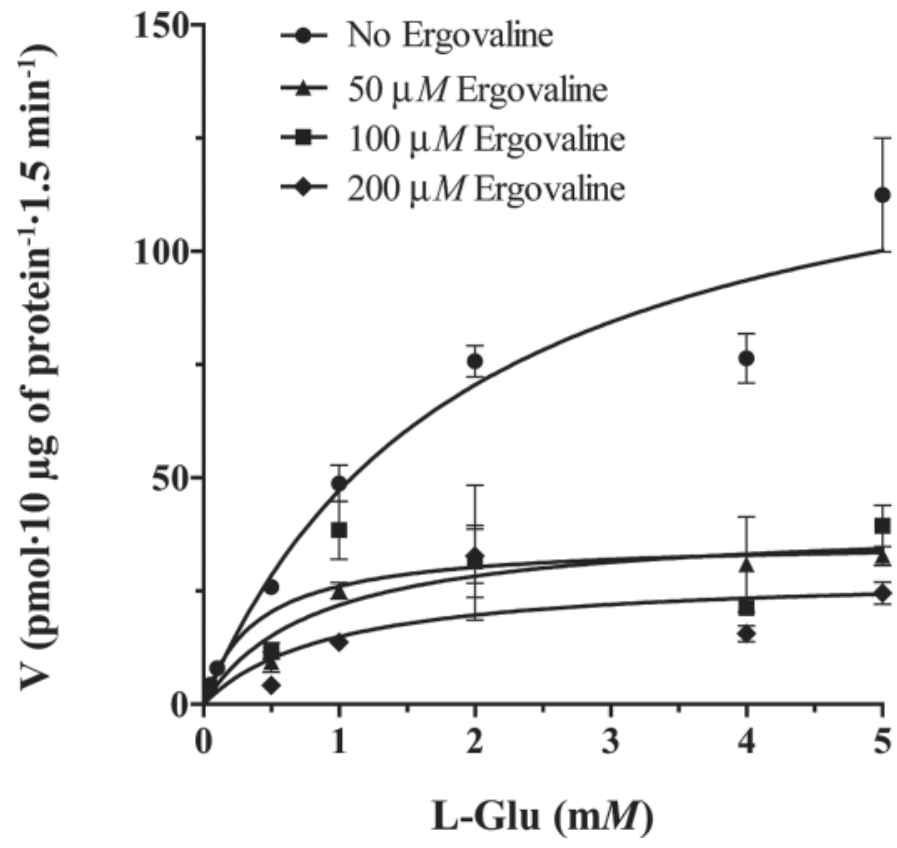

Figure 5. Kinetic analysis of ergovaline inhibition of L-glutamate (Glu) uptake by bovine cerebral synaptic vesicles (SV). Values are means $(\mathrm{n}=9) \pm$ standard error Glu uptake (pmol.10 $\mu \mathrm{g}$ of SV pro$\operatorname{tein}^{-1} \cdot 1.5 \mathrm{~min}^{-1}$ ) from 3 separate experiments. Kinetic analyses were performed using the Michaelis-Menten equation. In the absence of ergovaline, apparent Michaelis constant $\left(K_{\mathrm{m}}\right.$, measuring affinity) and maximum reaction rate $\left(V_{\max }\right)$ values for Glu uptake were $1.53 \pm 0.18$ $\mu M$ and $148 \pm 55.1$ (pmol/1.5 min), respectively. In the presence of 50, 100, or $200 \mu M$ ergovaline, apparent $K_{\mathrm{m}}$ and $V_{\max }$ values for Glu uptake were $0.77 \pm 0.14$ and $39.9 \pm 14.48 ; 0.61 \pm 0.26$ and $38.8 \pm$ 2.28 ; and $1.16 \pm 0.34 \mu M$ and $30.4 \pm 4.40 \mathrm{pmol} / 1.5 \mathrm{~min}$, respectively. No ergovaline effect $(P=0.332)$ on apparent $K_{\mathrm{m}}$ occurred. Equal $(P$ $\geq 0.765)$ effect $(P=0.016)$ of 50,100 , or $200 \mu M$ of ergovaline on apparent $V_{\max }$.

\section{DISCUSSION}

\section{Validation of Bovine Cerebral SV Model to Measure VGLUT Activity}

A bovine cerebral SV model was successfully developed to test the general hypothesis that ergopeptine alkaloids commonly present in endophyte-infected tall fescue inhibit VGLUT-like activity in bovine cerebral SV. Development of the model was based on a previously-described bovine SV isolation procedure (Carlson et al., 1989; Kish and Ueda, 1989) to study VGLUTlike activity. Using immunoblot analysis, the present study has extended our understanding of this model by demonstrating that VGLUT1, VGLUT2, vacuolar $\mathrm{H}^{+}$-ATPase 1 , and synaptophysin 1 are all expressed in the isolated SV (Figure 1).

In the cerebral cortex of nonruminants, VGLUT1 and VGLUT2 show complimentary localization, with VGLUT1 being homogeneously distributed throughout the cortex, whereas VGLUT2 is localized in layers IV and VI (Fremeau et al., 2004) and VGLUT function in $\mathrm{SV}$ is driven by a intra-SV-to-cytoplasmic $\mathrm{H}^{+}$gradient generated by vacuolar $\mathrm{H}^{+}$-ATPase 1 (Shigeri et al., 2004; Takamori, 2006). In addition, synaptophysin 1 is a membrane-bound glycoprotein exclusively found in SV (Jahn et al., 1985; Südhof, 1995). Therefore, our finding that bovine orthologs of these proteins are in SV indicates that bovines share the same complement of proteins responsible for VGLUT activity as do nonruminants.

\section{Glu Uptake by SV Is Inhibited by Compounds Known to Interact with Proteins Responsible for VGLUT Activity}

Vesicular Glu transporter activity was strongly inhibited by the use of compounds known to inhibit various proteins that contribute to VGLUT activity (Figure 3). Bafilomycin (an inhibitor of vacuolar $\mathrm{H}^{+}$-ATPase), and FCCP (an $\mathrm{H}^{+}$ionophore) are commonly used to inhibit VGLUT-mediated glutamate uptake by lowering the vesicular $\mathrm{H}^{+}$-ATPase activity or by perturbing the proton motive force (Kish and Ueda, 1989; Shigeri et al., 2004). Thus, the inhibition of VGLUT activity found in bovine SV by bafilomycin and FCCP, respectively, is consistent with the presence of $\mathrm{H}^{+}$-ATPase and function in SV. Analogously, the inhibition of Glu uptake by rose bengal and bromocriptine is indicative of the presence of SV VGLUT activity, consistent with the potent ability of rose bengal (a polyhalogenated fluorescein derivative) and bromocriptine (a peptide-containing, halogenated ergopeptine) to inhibit VGLUT activity (Carlson et al., 1989; Ogita et al., 2001; Shigeri et al., 2004) and the identification of VGLUT1 and VGLUT2 in the SV. Overall, all 4 reagents inhibited Glu uptake by $\mathrm{SV}$, at levels consistent with those reported for rat SV (Thompson et al., 2005).

\section{Ergopeptines Differentially Inhibited SV VGLUT-Mediated Glu Uptake}

The ergopeptines evaluated in this study contain a common ergoline ring and a peptide moiety but the composition of their side groups differ (Figure 6). Bromocriptine is a manufactured chemical with a structure similar to the naturally occurring ergopeptines evaluated. Ergovaline, a predominant ergot alkaloid in endophyte-infected tall fescue, has been implicated in decreased productivity and health of cattle displaying symptoms of fescue toxicosis (Strickland et al., 2009), whereas ergocornine and ergotamine also are ergoline derivatives found in endophyte-infected tall fescue, but whose effect on physiological systems is less well defined. However, in rats at least, ergocornine decreases 


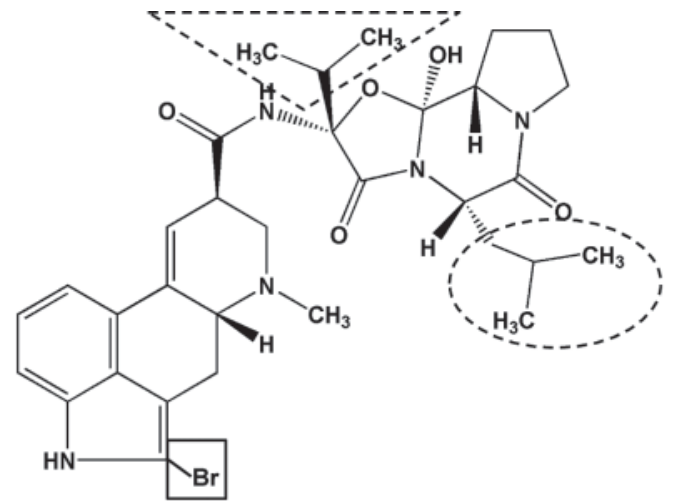

Bromocriptine

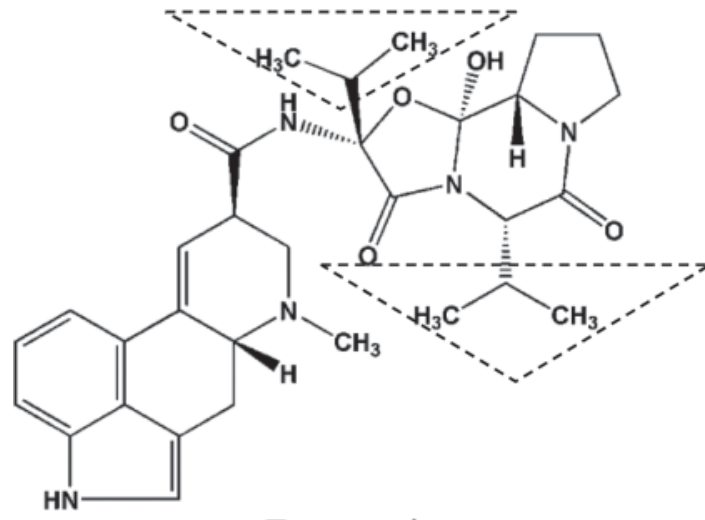

Ergocornine

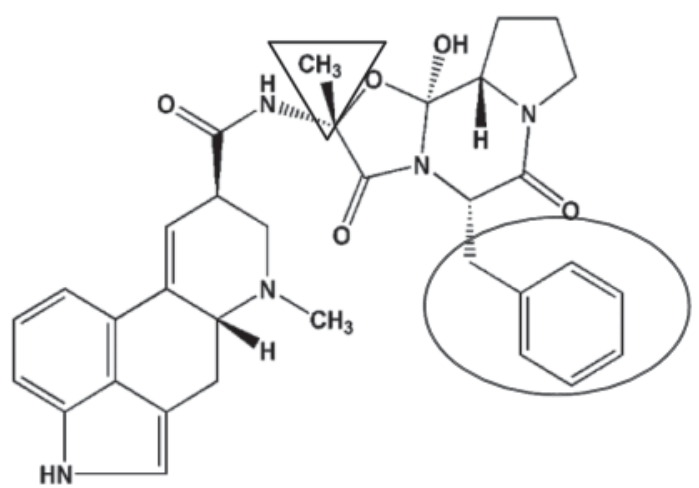

Ergotamine

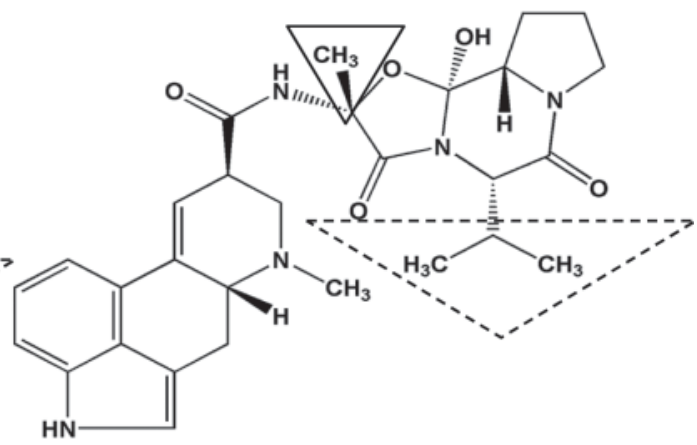

Ergovaline

Figure 6. Chemical structure of ergopeptine alkaloids used in the present study. Ergopeptine alkaloids are ergoline derivatives containing tricyclic peptide moieties that differ at side groups with respect to methyl (solid-line triangle), methyl benzyl (solid-line circle), isopropyl (dashed-line triangle), isobutyl (dashed-line circle), or bromo (solid-line square). Adapted from Klotz et al. (2010).

plasma levels of progesterone and prolactin (Tomogane et al., 1975).

Whereas all of these ergopeptines strongly inhibited bovine VGLUT activity by 80 to $90 \%$ (Figure 4 ), the concentration required to inhibit SV VGLUT activity was spread over 2 orders of magnitude $\left(\mathrm{IC}_{50}\right.$ values of 2.8 to $137 \mu M$ ). Therefore, in vivo, the relative tissue concentrations of ergotamine, ergocornine, and ergovaline will dictate their relative physiological consequence. Species differences may exist in the sensitivity of VGLUT activity to ergopeptides, as $\mathrm{IC}_{50}$ values of 22 \pm 6 and $30 \pm 2 \mu M$ for bromocriptine and ergotamine have been reported, respectively, for rat SV (Carlson et al., 1989), using uptake conditions similar to those in the current study.

Because of its reputed role in fescue toxicosis, ergovaline was selected as a model ergopeptine to use in kinetic analyses to gain insight as to how bovine VGLUT activity is inhibited by ergopeptines. The finding that $V_{\max }$ for Glu uptake was decreased with increasing ergovaline concentrations, whereas $K_{\mathrm{m}}$ was not affected (Figure 5), indicates that ergovaline inhibition of VGLUT activity was through a noncompetitive mechanism. Thus, ergovaline could have bound allosterically to a non-Glu binding site of expressed VGLUT proteins, bound to another component of the VGLUT activity system (vacuolar $\mathrm{H}^{+}$-ATPase), or both.

\section{Potential Ramifications of Impaired VGLUT Activity}

In summary, a functional model to study effectors of bovine cerebral SV of VGLUT-mediated Glu uptake was developed and used to determine that 3 ergopeptines found in endophyte-infected tall fescue, and bromocriptine (synthetic model ergopeptine), inhibit VGLUT activity up to about $80 \%$. However, different amounts of inhibitor were required to achieve this common level of inhibition. In addition, ergovaline was found to exert its inhibitory action by a noncompetitive mechanism. Because both the VGLUT and vacuolar $\mathrm{H}^{+}$-ATPase components of the VGLUT activity system were identified in SV, the mechanism of ergovaline 
action could have been through allosteric binding of VGLUT1, VGLUT2, or of vacuolar $\mathrm{H}^{+}$-ATPase.

Previous mechanistic research models have demonstrated the negative effect of specific ergopeptines on dopaminergic and serotoninergic neurotransmission through their binding of dopamine (Larson et al., 1995, 1999) and serotoninergic (Haddjeri et al., 1998) receptors, respectively. Although glutamate transmission has yet to be determined in cattle or other ruminants (at least it is not known to the authors), the findings of this study suggest that cattle with fescue toxicosis also may have a decreased glutamatergic neurotransmission capacity. Because at least the gastrointestinal tract of guinea pigs is innervated by glutamatergic neurons (Liu et al., 1997; Tsai, 2005); the glutamatergic neurons of the ileum of guinea pigs, mice, and humans express functional metabotropic glutamate receptor 8 (mGLuR8) and mGLuR8 may be involved with regulation of cholinergic-dependent gut contractions (Tong and Kirchgessner, 2003); and the posit that glutamate neurotransmission is the primary route of transmitting mucosa-derived afferent information to the enteric plexuses and brain (Tong et al., 2001); the findings of the current study suggest that ergopeptine-inhibition of glutamatergic function may be one mechanism by which cattle consuming endophyte-infected tall fescue have impaired feed digestion. In keeping, i.v. administration of ergotamine and ergovaline results in decreased frequency of cyclic contractions and increased tonus of both the reticulum and rumen (McLeay and Smith, 2006) and at least part of the inhibitory effect of i.v. infusion of ergotamine on reticular motility of sheep is thought to occur through myenteric neurons (Poole et al., 2009).

Besides potential involvement of impaired VGLUT activity in afferent/sensory neural circuits, some evidence suggests that the inhibition of VGLUT activity by ergopeptides may result in impaired efferent neuronal signaling. That is, functional VGLUT2-mediated signaling in glutamatergic neurons is an obligate component of the respiratory rhythm generator but not locomotion (at least in mice; Wallén-Mackenzie et al., 2006; Gezelius et al., 2006), and both ergovaline and ergotamine depress the respiratory rate of sheep (McLeay et al., 2002).

Because expression of VGLUT and $\mathrm{H}^{+}$-ATPase is not restricted to the central nervous system, another important implication from the findings of this study is that consumption of ergopeptines may deleteriously affect the function of many cell types/tissues. For example, in Angus heifers, it has been demonstrated that a single i.v. infusion dose (about $21 \mu \mathrm{g} / \mathrm{kg}$ of BW) of ergotamine administration decreases plasma prolactin levels by $75 \%$ over a 4 h-period (Browning, Jr. and
Leite-Browning, 1997a). In yearling Angus steers, using an identical administration regimen, a single i.v. infusion dose (about $24 \mu \mathrm{g} / \mathrm{kg}$ of BW) of ergotamine administration decreases plasma prolactin and LH concentrations by 77 and 21\%, respectively (Browning, Jr. et al., 1997b). In pregnant dairy cows, after a single dose of ergotamine (about $19 \mu \mathrm{g} / \mathrm{kg}$ of BW), plasma prolactin levels were decreased about $70 \%$ for 1 to $4 \mathrm{~h}$ after ergotamine administration, whereas plasma LH concentrations were decreased $11 \%$ within the fourth hour (Browning et al., 1998). Although speculative, our finding that ergotamine inhibits VGLUT activity (Figure 4) suggests that the observed inhibition of LH plasma concentrations in beef steers and pregnant dairy cows (Browning et al., 1997b, 1998) treated with ergotamine may have resulted from ergotamine inhibition of LH-secreting gonadotrophs, when considered with the understanding that LH gonadotrophs are known to highly express VGLUT2 (Hrabovszky et al., 2006). If so, then one mechanism by which consumption of ergopeptines decreases plasma LH secretion, and therefore corpus luteum development and function, is through ergotamine inhibition of VGLUT2 function in gonadotrophs.

Vesicular Glu transporters also are expressed in other nonneuronal tissues such as synaptic-like microvesicles in pinealocytes of the pineal gland (VGLUT1 and 2; Morimoto et al., 2003), pancreatic $\alpha$ - and F-cells (VGLUT1 and 2; Hayashi et al., 2003b), intestinal L cells (VGLUT2; Hayashi et al., 2003a), osteoblasts of bone (VGLUT1; Hinoi et al., 2002), and spermatids of testes (VGLUT1 and 2; Hayashi et al., 2003a). More specifically, it is thought that VGLUT in these tissues act as endocrine, paracrine, and autocrine modulators of cellular function in these tissues (Moriyama and Omote, 2008). However, whether cattle (and other consumers of endophyte-infected tall fescue) express system VGLUT components outside of SV, and whether they are involved in the regulation of cellular function as for other mammals, remains to be determined.

\section{REFERENCES}

Aiken, G. E., B. H. Kirch, J. S. Strickland, L. P. Bush, M. L. Looper, and F. N. Schrick. 2007. Hemodynamic responses of the caudal artery to toxic tall fescue in beef heifers. J. Anim. Sci. 85:23372345 .

Aiken, G. E., J. S. Strickland, M. L. Looper, L. P. Bush, and F. N. Schrick. 2009. Hemodynamics are altered in the caudal artery of beef heifers fed different ergot alkaloid concentrations. J. Anim. Sci. 87:2142-2150.

Bellocchio, E. E., R. J. Reimer, R. T. Fremeau, and R. H. Edwards. 2000. Uptake of glutamate into synaptic vesicles by an inorganic phosphate transporter. Science 289:957-960.

Brown, K. R., G. A. Anderson, K. Son, G. Rentfrow, L. P. Bush, J. L. Klotz, J. R. Strickland, J. A. Boling, and J. C. Matthews. 2009. Growing steers grazing high versus low endophyte (Neotyphodium 
coenophialum)-infected tall fescue have reduced serum enzymes, increased hepatic glucogenic enzymes, and reduced liver and carcass mass. J. Anim. Sci. 87:748-760.

Browning, R., Jr., and M. L. Leite-Browning. 1997a. Effect of ergotamine and ergonovine on thermal regulation and cardiovascular function in cattle. J. Anim. Sci. 75:176-181.

Browning, R., F. N. Schrick, F. N. Thompson, and T. Wakefield Jr. 1998. Reproductive hormonal responses to ergotamine and ergonovine in cows during the luteal phase of the estrous cycle. J. Anim. Sci. 76:1448-1454

Browning, R., Jr., F. N. Thompson, J. L. Sartin, and M. L. LeiteBrowning. 1997b. Plasma concentrations of prolactin, growth hormone, and luteinizing hormone in steers administered ergotamine or ergonovine. J. Anim. Sci. 75:796-802.

Carlson, M. D., P. E. Kish, and T. Ueda. 1989. Glutamate uptake into synaptic vesicles: Competitive inhibition by bromocriptine. J. Neurochem. 53:1889-1894.

Dyer, D. C. 1993. Evidence that ergovaline acts on serotonin receptors. Life Sci. 53:PL223-PL228.

Fremeau, R., T. Jr., S. Voglmaier, R. P. Seal, and R. H. Edwards 2004. VGLUTs define subsets of excitatory neurons and suggest novel roles for glutamate. Trends Neurosci. 27:98-103.

Fremeau, R. T., M. D. Troyer, I. Pahner, G. O. Nygaard, C. H. Tran, R. J. Reimer, E. E. Bellocchio, D. Fortin, J. Storm-Mathisen, and R. H. Edwards. 2001. The expression of vesicular glutamate transporters defines two classes of excitatory synapse. Neuron $31: 247-260$.

Gezelius, H., A. Wallén-Mackenzie, A. Enjin, M. Lagerström, and K. Kullander. 2006. Role of glutamate in locomotor rhythm generating neural circuitry. J. Physiol. Paris 100:297-303.

Haddjeri, N., B. Seletti, F. Gilbert, C. de Montigny, and P. Blier 1998. Effect of ergotamine on serotonin-mediated responses in the rodent and human brain. Neuropsychopharmacology 19:365-380.

Hayashi, M., R. Morimoto, A. Yamamoto, and Y. Moriyama. 2003a Expression and localization of vesicular glutamate transporters in pancreatic islets, upper gastrointestinal tract, and testis. J. Histochem. Cytochem. 51:1375-1390.

Hayashi, M., H. Yamada, S. Uehara, R. Morimoto, A. Muroyama, S. Yatsushiro, J. Takeda, A. Yamamoto, and Y. Moriyama. 2003b. Secretory granule-mediated co-secretion of L-glutamate and glucagon triggers glutamatergic signal transmission in islets of Langerhans. J. Biol. Chem. 278:1966-1974.

Hemken, R. W., J. A. Boling, L. S. Bull, R. H. Hatton, R. C. Buckner, and L. P. Bush. 1981. Interaction of environmental temperature and anti-quality factors on the severity of summer fescue toxicosis. J. Anim. Sci. 52:710-714.

Hinoi, E., S. Fujimori, T. Takarada, H. Taniura, and Y. Yoneda. 2002. Facilitation of glutamate release by ionotropic glutamate receptors in osteoblasts. Biochem. Biophys. Res. Commun. 297:452-458.

Howell, J. A., A. D. Matthews, K. C. Swanson, D. L. Harmon, and J. C. Matthews. 2001. Molecular identification of high-affinity glutamate transporters in sheep and cattle forestomach, intestine, liver, kidney, and pancreas. J. Anim. Sci. 79:1329-1336.

Hrabovszky, E., I. Kalló, G. F. Turi, K. May, G. Wittmann, C. Fekete and Z. Liposits. 2006. Expression of vesicular glutamate transporter-2 in gonadotrope and thyrotrope cells of the rat pituitary. Regulation by estrogen and thyroid hormone status. Endocrinology 147:3818-3825.

Ikemoto, A., D. G. Bole, and T. Ueda. 2003. Glycolysis and glutamate accumulation into synaptic vesicles. J. Biol. Chem. 278:5929 5940

Jackson, J. A., Jr., R. W. Hemken, J. A. Boling, R. J. Harmon, R. C. Buckner, and L. P. Bush. 1984. Summer fescue toxicosis in dairy steers fed tall fescue seed. J. Anim. Sci. 58:1057-1061.

Jahn, R., W. Schiebler, C. Ouimet, and P. Greengard. 1985. A 38,000 -dalton membrane protein (p38) present in synaptic vesicles. Proc. Natl. Acad. Sci. USA 82:4137-4141.

Kilberg, M. S. 1989. Measurement of amino acid transport by hepatocytes in suspension and monolayer culture. Methods Enzymol. $173: 564-575$
Kish, P. E., and T. Ueda. 1989. Glutamate accumulation into synaptic vesicles. Methods Enzymol. 174:9-25.

Klotz, J. L., B. H. Kirch, G. E. Aiken, L. P. Bush, and J. R. Strickland. 2010. Contractile response of fescue-naïve bovine lateral saphenous veins to increasing concentrations of tall fescue alkaloids. J. Anim. Sci. 88:408-415.

Krnjević, K. 2010. When and why amino acids? J. Physiol. 588:33-44. Laemmli, U. K. 1970. Cleavage of structural proteins during the assembly of the head of bacteriophage T4. Nature 227:680-685.

Larson, B. T., D. L. Harmon, E. L. Piper, L. M. Griffis, and L. P. Bush. 1999. Alkaloid binding and activation of D2 dopamine receptors in cell culture. J. Anim. Sci. 77:942-947.

Larson, B. T., M. D. Samford, J. M. Camden, E. L. Pier, M. S. Kerley, J. A. Paterson, and J. T. Turner. 1995. Ergovaline binding and activation of D2 dopamine receptors in GH4ZR7 cells. J. Anim. Sci. 73:1396-1400.

Liu, M.-T., J. D. Rothstein, M. D. Gershon, and A. L. Kirchgessner 1997. Glutamatergic enteric neurons. J. Neurosci. 17:4764-4784.

McLeay, L. M., and B. L. Smith. 2006. Effects of ergotamine and ergovaline on the electromyographic activity of smooth muscle reticulum and rumen of sheep. Am. J. Vet. Res. 67:707-714.

McLeay, L. M., B. L. Smith, and G. W. Reynolds. 2002. Cardiovascular, respiratory, and body temperature responses of sheep to the ergopeptides ergotamine and ergovaline. Am. J. Vet. Res. 63:387-393

Mizinga, K. M., F. N. Thompson, J. A. Stuedemann, and T. E. Kiser. 1992. Effects of feeding diets containing endophyte-infected fescue seed on luteinizing hormone secretion in postpartum beef cows and in cyclic heifers and cows. J. Anim. Sci. 70:3483-3489.

Monroe, J. L., D. L. Cross, L. W. Hudson, D. M. Hendricks, S. W. Kennedy, and W. C. Bridges Jr. 1988. Effect of selenium and endophyte-contaminated fescue on performance and reproduction in mares. J. Equine Vet. Sci. 8:148-153.

Morimoto, R., M. Hayashi, S. Yatsushiro, M. Otsuka, A. Yamamoto and Y. Moriyama. 2003. Co-expression of vesicular glutamate transporters (VGLUT1 and VGLUT2) and their association with synaptic-like microvesicles in rat pinealocytes. J. Neurochem. 84:382-391.

Moriyama, Y., and H. Omote. 2008. Vesicular glutamate transporter acts as a metabolic regulator. Biol. Pharm. Bull. 31:1844-1846.

Moriyama, Y., and A. Yamamoto. 2004. Glutamatergic chemical transmission: Look! Here, there, and anywhere. J. Biochem. $135: 155-163$.

Ogita, K., K. Hirata, D. G. Bole, S. Yoshida, Y. Tamura, A. M. Leckenby, and T. Ueda. 2001. Inhibition of vesicular glutamate storage and exocytotic release by Rose Bengal. J. Neurochem. 77:34-42.

Ozkan, E. D., and T. Ueda. 1998. Glutamate transport and storage in synaptic vesicles. Jpn. J. Pharmacol. 77:1-10.

Peng, S. B., X. Li, B. P. Crider, Z. Zhou, P. Andersen, S. J. Tsai, X. S. Xie, and D. K. Stone. 1999. Identification and reconstitution of an isoform of the $116-\mathrm{kDa}$ subunit of the vacuolar proton translocating ATPase. J. Biol. Chem. 274:2549-2555.

Poole, D. P., R. A. Littler, B. L. Smith, and L. M. McLeay. 2009. Effects and mechanisms of action of the ergopeptides ergotamine and ergovaline and the effects of peramine on reticulum motility of sheep. Am. J. Vet. Res. 70:270-276.

Schäfer, M. K.-H., H. Varoqui, N. Defamie, E. Weihe, and J. D. Erickson. 2002. Molecular cloning and functional identification of mouse vesicular glutamate transporter 3 and its expression in subsets of novel excitatory neurons. J. Biol. Chem. 277:50734-50748.

Shigeri, Y., R. P. Seal, and K. Shimamoto. 2004. Molecular pharmacology of glutamate transporters, EAATs and VGLUTs. Brain Res. Brain Res. Rev. 45:250-265.

Strickland, J. R., G. E. Aiken, D. E. Spiers, L. R. Fletcher, and J. W. Oliver. 2009. Physiological Basis of Fescue Toxicosis. Pages 203227 in Tall Fescue for the Twenty-first Century. H. A. Fribourg, D. B. Hannaway, and C. P. West, ed. American Society of Agronomy Inc., Crop Science Society of America Inc., and Soil Science Society of America Inc., Madison, WI.

Stuedemann, J. A., and C. S. Hoveland. 1988. Fescue endophyte: History and impact on animal agriculture. J. Prod. Agric. 1:39-44. 
Südhof, T. C. 1995. The synaptic vesicle cycle: A cascade of proteinprotein interactions. Nature 375:645-653.

Takamori, S. 2006. VGLUTs: 'Exciting' times for glutamatergic research? Neurosci. Res. 55:343-351.

Thompson, C. M., E. Davis, C. N. Carrigan, H. D. Cox, R. J. Bridges, and J. M. Gerdes. 2005. Inhibitor of the glutamate vesicular transporter. Curr. Med. Chem. 12:2041-2056.

Tomogane, H., K. Ôta, and A. Yokoyama. 1975. Suppression of progesterone secretion in lactating rats by administration of ergocornine and the effect of prolactin replacement. J. Endocrinol. 65:155-161.

Tong, Q., and A. L. Kirchgessner. 2003. Localization and function of metabotropic glutamate receptor 8 in the enteric nervous system. Am. J. Physiol. Gastrointest. Liver Physiol. 285:G992-G1003.
Tong, Q., J. Ma, and A. L. Kirchgessner. 2001. Vesicular glutamate transporter 2 in the brain-gut axis. Neuroreport 12:3929-3934.

Tsai, L. H. 2005. Function of GABAergic and glutamatergic neurons in the stomach. J. Biomed. Sci. 12:255-266.

Wallén-Mackenzie, A., H. Gezelius, M. Thoby-Brisson, A. Nygård, A. Enjin, F. Fujiyama, G. Fortin, and K. Kullander. 2006. Vesicular glutamate transporter 2 is required for central respiratory rhythm generation but not for locomotor central pattern generation. J. Neurosci. 26:12294-12307. 